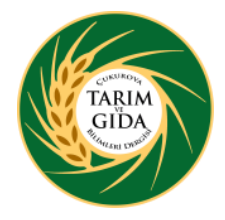

\title{
Burdur Gölü Çevresindeki Tuzlu ve Borlu Toprakların Islahı İçin Gerekli Yıkama Suyu Miktarı ve Islah Süresi
}

ÖZ

\author{
Barış BAHÇECI ${ }^{1 *}$, Ali Fuat TARI ${ }^{1}$, İdris BAHCECI ${ }^{1}$
}

Burdur Gölü çevresindeki tuzlu ve borlu toprakların ıslahı için gerekli yıkama suyu miktarı ile yıkama süresini belirlemek amacıyla bir tarla denemesi yürütülmüsştür. Aralıklı göllendirme yöntemi ile, toplam $300 \mathrm{~cm}$ yıkama suyu uygulanan denemeler sonunda, yıkama suyu miktarları ve infiltrasyon süreleri belirlenmiştir. Her yıkama uygulamasından sonra alınan toprak örnekleri analiz edilerek, toprak tuz değerleri $4.0 \mathrm{dS} \mathrm{m}^{-1}$ 'nin ve bor değerleri 2 ppm'in altına düşünce, yıkama uygulamaları sonlandırılmıştır. Verilerin değerlendirilmesiyle yıkama suyu derinliği ile yıkanan tuz ve bor oranları arasında yüksek korelasyon katsayılarına sahip ilişkiler bulunmuştur. Ayrıca uygulanan yıkama sularının infiltre olma süreleri belirlenmiştir. Bu ilişkilerin yardımıyla arpa ve şeker pancarı gibi tuza ve şeker pancarı gibi bora dayanıklı bitkilerin yetişebileceği düzeyde 1slah sağlamak için gerekli yıkama suyu miktarları ve 1slah süreleri hesaplanmıştır. Buna göre, tuz yıkanması için toprak derinliğinin 2 katı, bor yıkanması için toprak derinliğinin 2.2 katı yıkama suyu gerektiği hesaplanmıştır.

Anahtar Kelimeler: Borlu toprak, tuzluluk, çorak toprak, toprak 1slahı

\section{The required amount of Leaching water and reclamation period for the rehabilitation of salty and boron soils around Lake Burdur}

\begin{abstract}
A field trial was conducted to determine the amount of leaching water and the leaching time required for the improvement of the salty and boron soils around Burdur Lake. At the end of the trials, in which a total of $300 \mathrm{~cm}$ of leaching water was applied in $30 \mathrm{~cm}$ portions with the intermittent ponding method, the amount of leaching water and infiltration times were determined. Soil samples taken after each leaching application were analyzed, and when soil salt values fell below $4.0 \mathrm{dS} \mathrm{m}^{-1}$ and boron values below $2 \mathrm{ppm}$, leaching applications were terminated. By evaluating the data, relationships with high correlation coefficients were found between the leaching water depth and the leached salt and boron ratios. In addition, the infiltration times of the applied leaching waters were determined. With the help of these relations, the necessary amount of leaching water and reclamation times were calculated to ensure that plants tolerant to salinity such as barley and sugar beet, and boron tolerant plants such as sugar beet can be grown. Accordingly, it has been calculated that 2 times the soil depth for salt leaching and 2.2 times the soil depth for boron leaching are required.
\end{abstract}

Keywords: Boron soil, salinity, barren soil, soil reclamation

ORCID ID (Yazar sirasina göre)

0000-0002-9693-0653, 0000-0001-9157-1682, 0000-0001-9849-3939

Yayın Kuruluna Geliş Tarihi: 12.06.2021

Kabul Tarihi: 22.12.2021

${ }^{1}$ Harran Üniversitesi, Tarımsal Yapılar ve Sulama Bölümü, Şanlıurfa

*E-posta: baris_bahceci@hotmail.com 


\section{Giriş}

Toprak tuzluluğu, toprak verimliliğini ve bitkilerde su alımını azaltan toksik etkisi nedeniyle tüm dünyada giderek artan bir tehdittir. Dünyada birçok tarım ülkesi, yeterli gıda, yem ve lif üretimini engelleyen yoğun toprak tuzluluğu tehdidi altındadır (Sharma ve ark., 2016).

Tuzlu topraklar dünya çapında yaklaşık 954.8 milyon ha araziyi kaplar ve hemen hemen her kıtaya yayılmıştır (Pessarakli ve Szabolcs, 1999; FAO, 2021). Besin döngüsü, biyolojik çeşitlilik, tarım ve biyokütle üretimi gibi ekosistem hizmetlerinin kayb1 (Liu ve ark., 2012), arazi bozulum süreci ile ilişkilidir (Utset ve Borroto, 2001).

Bilindiği gibi, toprakların tuz ve bor içeriği artıkça, bu topraklarda yetişebilen ürün çeşitliliği giderek azalır ve birçok gıda ve lif bitkisi yerini tuza dayanıklı bitkilere bırakır. Tuzluluk arttıkça, kültür bitkilerinin yerini tuzcul bitkiler alır. Süreç durdurulamazsa, hiç ürün yetişmeyen topraklar giderek yayılır ve çölleşme başlar.

$\mathrm{Bu}$ süreci durdurmanın yolu tuz ve bordan etkilenen toprakların 1slah edilerek geri kazanılmasından geçer. Ancak bu süreç oldukça zaman alıcı ve zahmetlidir. Bitki kök bölgesini tuz veya bordan arındırmak için, toprak özelliklerine göre değişmekle beraber, devasa miktarlarda suya gerek duyulur. Ağır bünyeli topraklarda suyun infiltre olması uzun zaman alır. Üstelik bu sirada uygulanan suyun önemli bir bölümü buharlaşır ve yıkama randımanı düşer. $\mathrm{Bu}$ yüzden, yıkama işlemlerinin bitki yetişme döneminde yapılması su temini açısından sorunlar yaratır. Aslında küresel isınma ile birlikte giderek kıtlaşan su, sanılandan daha büyük bir sorundur.

Islah için gerekli olan yıkama suyu miktarı ve 1slah süresinin doğru olarak belirlenmesi, tuzlu ve borlu toprakların iyileştirilmesinde karşılaşılan en önemli sorunlardan biridir. Birçok deneysel ve kuramsal araştırmadaki temel amaç, yıkama suyu miktarının hesaplanması için toprakta su hareketine ilişkin yasalara uygun olarak, fonksiyonel bir formülün belirlenmesidir. Dünyada tuzlu toprakların 1slahı konusunda çalışan bilim adamları çalışmalarının önemli bölümünü bu konuya ayırmıştır. Şimdiye kadar araştırmacılar pek çok sayıda eşitlik kullanılmasını önermişlerdir (Reeve, 1955; Dielman, 1963; Nielsen ve ark., 1966; Kovda, 1967; Oster ve ark., 1972; Hoffman, 1986; Van Hoorn ve Van Alphen, 1990).

Tuzlu topraklar dahil olmak üzere toprak kalitesinin korunması ve bozulmuş alanların yönetimi ve restorasyonu ile ilgili çok sayıda öneri bulunmaktadır (Chaturvedi ve ark., 1987; Mishra ve ark., 2002; Dagar ve ark., 2006; Abhilash ve ark.; 2012; Dubey ve ark, 2019; Tripathi ve ark., 2019; Edrisi ve ark., 2020;).

Ancak toprak, su ve yerel koşullardaki değişkenlik nedeniyle önerilen eşitliklerin uygulanmasında genellikle bazı eksiklikler ortaya çıkmıştır. $\mathrm{Bu}$ yüzden yerinde yapılan tarla denemelerinden elde edilen verilerin kullanılmas1 en doğru seçenek olarak görülmektedir. Bu bağlamda Türkiye'de de birçok tarla denemesi yürütülmüştür (Beyce, 1977; Bahçeci, 1983. Bahçeci, 1984.; Özden ve Ören, 1986; Saatç1lar, 1991; Sönmez ve ark., 1996).

Bu çalışma ile Burdur Gölü çevresindeki tuzlu ve borlu toprakların sslah edilerek tarımsal üretime kazandırılması için gerekli su miktarı ile ıslah süresi belirlenmiştir.

\section{Materyal ve Yöntem \\ Deneme Yeri}

Burdur ili ve çevresinde tamamen tarım dış1 1516 bin hektar çorak arazi bulunmaktadır (TOPRAKSU, 1978). Bu yüzden deneme, Türkiye'nin Burdur Göller Bölgesi'nde yürütülmüştür. Deneme yeri, ortalama $845 \mathrm{~m}$ yükseklikte bulunan Burdur Gölü mansabinda yer alan tuzlu ve borlu topraklardır. Burdur Gölü, büyüklügü bakımından Türkiye'nin yedinci gölüdür. Koordinatları $37^{\circ} 45^{\prime}$ Kuzey, $30^{\circ} 12^{\prime}$ Doğu'dur. Ortalama göl alanı $153 \mathrm{~km}^{2}$, denizden yüksekliği 842 metredir. (Şekil 1). 


\section{Burdur Gölü Çevresindeki Tuzlu ve Borlu Toprakların Islahı İçin Gerekli Yıkama Suyu Miktarı ve Islah Süresi}

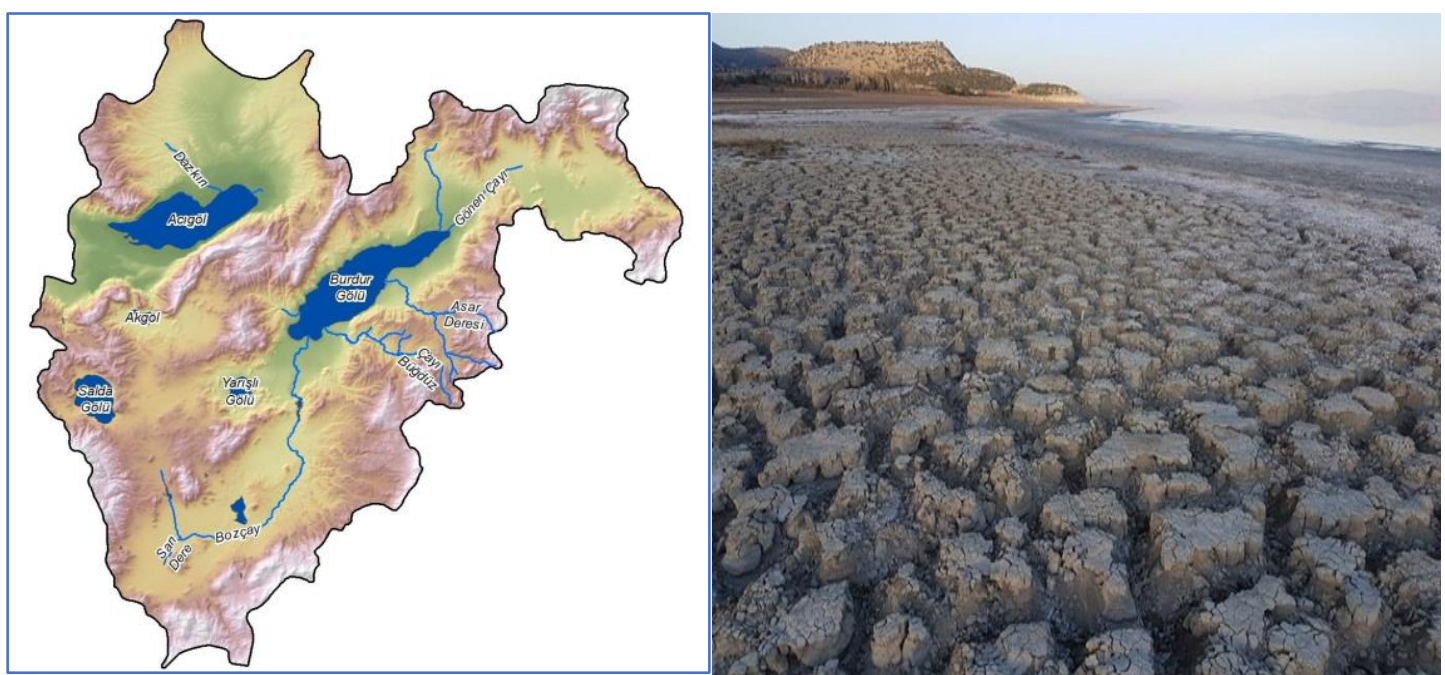

Şekil 1. Burdur Gölü ve çevresindeki çorak topraklar

\section{İklim özellikleri}

Yaz döneminde hava sıcak ve kurak, kış aylarında ise soğuk ve kar yağışlıdır. Uzun yıllık ortalama yağış 447 mm'dir. 1980'den 1995'e kadar havzada 500 mm'nin üzerinde yağış görülmezken; 19952010 döneminde havzada altı defa yıllık 500 mm'nin üzerinde yağış kaydedilmiştir.

\section{Toprak özellikleri}

Havzadaki çorak topraklar Burdur gölünün güneybatısında ve kuzey doğusunda parçalar halinde olup yaklaşık 15.000 ha'lık bir alanı kaplamaktadır. Güney ve kuzeyde ise alüvyonların birikmesiyle, sazlarla kaplı tuzlu bataklık görünümündeki kıyı ovaları ve delta oluşumu görülmektedir (DSİ, 2016). Araştırma alanı toprakları 1800 ha'lık bir alanı kaplar ve intrazonal topraklarin halomorfik alt ordosuna dahildir (TOPRAKSU, 1975). Topraklar çoğunlukla ince bünyeli olup, yüksek miktarda kireç içerirler. Toprak tuzluluğu çok yüksektir ve baskın tuz türü sodyum sülfat, klor ve karbonat olup, toprak $\mathrm{pH}^{\prime} 1 \quad 9.60$ ile 10.0 arasinda değişmektedir (Çizelge 1).

Y1kama suyu olarak kullanılan suyun elektriksel iletkenliği yaklaşık $0.661 \mathrm{dS} \mathrm{m}{ }^{-1}$, SAR değeri 1.667 olarak hesaplanmıştır (Çizelge 2). Deneme yerindeki taban suyunun EC değeri $1.72 \mathrm{dS} \mathrm{m}^{-1}$ ve SAR değeri 8.2'dir.

Çizelge 1. Deneme parsellerinin test öncesi toprak kimyasal ve fiziksel özellikleri

\begin{tabular}{|c|c|c|c|c|c|c|c|c|c|}
\hline \multirow{2}{*}{$\begin{array}{l}\text { Toprak } \\
\text { derinliği, } \\
\quad \mathrm{cm}\end{array}$} & \multirow{2}{*}{$\begin{array}{c}\text { Doyma } \\
\%\end{array}$} & \multirow{2}{*}{ Tekstür } & \multirow{2}{*}{$\begin{array}{l}\text { Volüm } \\
\text { ağırlığg1 }\end{array}$} & \multirow{2}{*}{$\mathrm{pH}$} & \multirow{2}{*}{$\begin{array}{c}\mathrm{EC}_{\mathrm{e}} \\
\mathrm{dS} \mathrm{m}^{-1}\end{array}$} & \multicolumn{4}{|c|}{ Katyonlar, me $1^{-1}$} \\
\hline & & & & & & $\mathrm{Ca}$ & $\mathrm{Mg}$ & $\mathrm{Na}$ & K \\
\hline $0-20$ & 92 & $\mathrm{C}$ & 1.36 & 9.6 & 13.6 & 1.8 & 1.2 & 159 & 0.5 \\
\hline $20-40$ & 90 & $\mathrm{C}$ & 1.42 & 9.9 & 13.5 & 2.9 & 0.2 & 194 & 0.4 \\
\hline $40-60$ & 92 & $\mathrm{C}$ & 1.35 & 9.8 & 13.5 & 0.3 & 2.0 & 188 & 0.3 \\
\hline $60-80$ & 86 & $\mathrm{C}$ & 1.41 & 10.0 & 13.3 & 1.8 & 0.7 & 176 & 0.2 \\
\hline $80-100$ & 107 & $\mathrm{C}$ & 1.39 & 9.8 & 10.4 & 1.3 & 0.2 & 141 & 0.2 \\
\hline
\end{tabular}




\section{Burdur Gölü Çevresindeki Tuzlu ve Borlu Toprakların Islahı İçin Gerekli Yıkama Suyu Miktarı ve Islah Süresi}

\begin{tabular}{|c|c|c|c|c|c|c|c|}
\hline \multirow{3}{*}{$\begin{array}{c}\begin{array}{r}\text { Toprak } \\
\text { derinliği } \\
\mathrm{cm}\end{array} \\
0-20\end{array}$} & \multicolumn{4}{|c|}{ Anyonlar, } & \multirow{3}{*}{$\begin{array}{c}\text { Katyonlar } \\
\text { toplam1; } \\
\text { me } 1^{-1} \\
163\end{array}$} & \multirow{3}{*}{$\begin{array}{c}\text { B } \\
\mathrm{mg} \mathrm{l}^{-1} \\
11.3\end{array}$} & \multirow{3}{*}{$\begin{array}{c}\text { Kireç } \\
\% \\
26\end{array}$} \\
\hline & \multicolumn{4}{|c|}{$\mathrm{me} \mathrm{l}^{-1}$} & & & \\
\hline & $\mathrm{CO}_{3}$ & $\mathrm{HCO}_{3}$ & $\mathrm{Cl}$ & $\mathrm{SO}_{4}$ & & & \\
\hline $20-40$ & 8.4 & 15.8 & 60 & 79.3 & 198 & 12.7 & 40 \\
\hline $40-60$ & 17.2 & 12.0 & 86 & 82.2 & 189 & 10.7 & 45 \\
\hline $60-80$ & 18.4 & 11.8 & 94 & 66.4 & 179 & 16.3 & 37 \\
\hline $80-100$ & 23.2 & 10.0 & 92 & 53.6 & 143 & 15.8 & 46 \\
\hline
\end{tabular}

Toprak ve suyun fiziksel ve kimyasal analizleri Richards (1954)'e göre, toprak bünyesi hidrometre yöntemiyle Bouyoucos (1951)'e göre; karbonatlar kalsimetre yöntemiyle, tuzluluk toprak özütünde elektriksel iletkenlik $\left(\mathrm{EC}_{\mathrm{e}}\right)$ ile belirlendi. Sulama suyunun tuzluluk ve sodyumluluk oluşturma tehlikesi olmamasına rağmen, yeraltı suları tuzlu ve su tablası seviyesi yüksektir. Aynı zamanda, yüksek buharlaşma, toprakların tuzlu ve borlu olmasinın esas nedenidir.

Çizelge 2. Islah için kullanılan yıkama suyunun kimyasal özellikleri

\begin{tabular}{|l|l|l|l|l|l|l|l|l|l|l|c|}
\hline & EC & \multicolumn{4}{|c|}{ Katyonlar, $\mathrm{me} \mathrm{l}^{-1}$} & \multicolumn{3}{|l|}{ Anyonlar $\mathrm{me} \mathrm{l}^{-1}$} & Top & $\mathrm{B}$ \\
\hline $\mathrm{pH}$ & $\mathrm{dS} \mathrm{m}$ & $\mathrm{Na}$ & $\mathrm{K}$ & $\mathrm{Ca}$ & $\mathrm{Mg}$ & $\mathrm{CO}_{3}$ & $\mathrm{HCO}_{3}$ & $\mathrm{Cl}$ & $\mathrm{SO}_{4}$ & & $\mathrm{mg} \mathrm{l}^{-1}$ \\
\hline 8.2 & 0.661 & 1.62 & 0.04 & 2.03 & 3.52 & - & 5.29 & 1.04 & 0.88 & 7.2 & 0.1 \\
\hline
\end{tabular}

\section{İşlemler}

\section{Test yeri}

Burdur ilinde bulunan sorunlu toprakları temsil etmesi ve tuzlu yeraltı suyundan etkilenmemesi için özenle seçilmiştir. Deneme alanı, tuz yıkama denemeleri için tasarlanmıştır; bu denemelerden ayrıca infiltrasyon verileri de elde edilmiştir.

Parsel boyutları $3 \mathrm{~m} \times 4 \mathrm{~m}=12 \mathrm{~m}^{2}$ olarak düzenlenmiştir.

Yıkama suları aralıklı göllendirme yöntemi ile uygulanmıştır. Deneme süresince tüm parsellere uygulanan su miktarları düzenli olarak ölçülmüsstür. Yıkama öncesi ve 30, 90, 120, 150, 270 ve $300 \mathrm{~cm}$ y1kama suyu uygulandiktan sonra her parselden 20, 40, 6080 ve $100 \mathrm{~cm}$ derinliklerden toprak örnekleri alınmıştır. Toprak profilindeki tuzluluk değerleri $4 \mathrm{dS} \mathrm{m}^{-1}$ 'in altına düştüğünde yıkama suyu uygulamaları sonlandırılmıştır.

\section{Verilerin değerlendirilmesi}

Toprakların infiltrasyon kapasitelerini belirlemek için her $30 \mathrm{~cm}$ su derinliği ve her parsel için su uygulama zaman1 ve infiltre olma zamanı kaydedilmiştir. Daha sonra, her yıkama işlemi için bu değerlerin ortalaması hesaplanmıştır. Eklenik sızma (Z) miktarı ile ortalama eklenik zaman değerleri kullanılarak infiltrasyon eşitliği aşağıdaki eşitlikle belirlenmiştir (Kostiakov, 1932).

$\mathrm{Z}=\mathrm{KT}^{\mathrm{n}}$ 


\section{Burdur Gölü Çevresindeki Tuzlu ve Borlu Toprakların Islahı İçin Gerekli Yıkama Suyu Miktarı ve Islah Süresi}

ve $n$; üstür.

Tuz ve bor yıkanması

Tüm değerlendirmelerde üç parselin aritmetik ortalamaları kullanılmıştır. Yıkama sonrası toprakta kalan tuz veya bor konsantrasyonu (C), başlangıç konsantrasyonuna $\left(\mathrm{C}_{0}\right)$ bölünerek her yıkama suyu derinliği için $\mathrm{C} / \mathrm{C}_{0}$ değerleri elde edilmiştir. Her yıkama suyu derinliği $\left(\mathrm{D}_{\text {lw }}\right)$ toprak derinliğine $\left(\mathrm{D}_{\mathrm{s}}\right)$ bölünerek $\mathrm{D}_{\mathrm{lw}} / \mathrm{D}_{\mathrm{s}}$ oranları hesaplanmıştır. Böylece, yıkama suyunun derinliği ve uzaklaştırılan tuz veya bor konsantrasyonu, toprak derinliğinden bağımsız hale getirilerek, Reeve (1955) tarafindan rapor edildiği gibi tuz ve bor yıkama eğrisi elde edilmiştir.
Burada K, infiltrasyon katsayıs1, T; zaman (h) .

\section{Bulgular ve tartışma}

Tuz Yıkanması

Farklı yıkama suyu seviyeleri için elde edilen veriler, toprak profilinden yıkanan tuzların, yıkama suyu ile daha derinlere doğru yıkandığını göstermektedir (Çizelge 3). İlk yıkamada, tuzluluk düşüşü şiddetliydi ve tuzlar üst topraktan alt toprak katmanlarına y1kand1. Y1kama suyu uygulamalarının başlangıcında toprak tuzluluğu hızla azalırken, $\quad 150 \mathrm{~cm}$ yıkama suyu uygulamasından sonra yavaşlamıştır.

Çizelge 3. Farklı toprak katmanları için, yıkama suyu derinliğine karşı toprak tuzluluğu

\begin{tabular}{l|c|c|c|c|c|c|}
\hline \multirow{2}{*}{$\begin{array}{l}\text { Toprak } \\
\text { derinliği, } \\
\text { cm }\end{array}$} & 0 & \multicolumn{7}{c}{ Toprak tuzluluğu, dS m ${ }^{-1}$} \\
\cline { 2 - 7 } & \multicolumn{7}{c}{30} & \multicolumn{7}{c}{270} & 300 \\
\hline $0-20$ & 13.6 & 7.0 & 5.8 & 5.1 & 5.4 & 4.9 \\
\hline $20-40$ & 13.5 & 9.5 & 6.8 & 3.7 & 4.9 & 4.4 \\
\hline $40-60$ & 13.5 & 11.8 & 8.3 & 5.4 & 3.2 & 3.4 \\
\hline $60-80$ & 13.3 & 12.4 & 10.7 & 7.4 & 4.7 & 3.4 \\
\hline $80-100$ & 10.4 & 10.4 & 10.0 & 9.2 & 5.3 & 5.1 \\
\hline & & & & & & \\
\hline 20 & 13.6 & 7.0 & 5.8 & 5.1 & 5.4 & 4.9 \\
\hline 40 & 13.6 & 8.3 & 6.3 & 4.4 & 5.2 & 4.7 \\
\hline 60 & 13.5 & 9.4 & 7.0 & 4.7 & 4.5 & 4.2 \\
\hline 80 & 13.5 & 10.2 & 7.9 & 5.4 & 4.6 & 4.0 \\
\hline 100 & 12.9 & 10.2 & 8.3 & 6.2 & 4.7 & 4.2 \\
\hline
\end{tabular}

Çizelge 4. Yıkama sularına karşı toprakta kalan tuz yüzdesi

\begin{tabular}{|c|c|c|c|c|c|c|}
\hline 20 & 1.0 & 0.51 & 0.43 & 0.38 & 0.40 & 0.36 \\
\hline 40 & 1.0 & 0.61 & 0.46 & 0.32 & 0.38 & 0.34 \\
\hline 60 & 1.0 & 0.70 & 0.51 & 0.35 & 0.33 & 0.31 \\
\hline 80 & 1.0 & 0.76 & 0.59 & 0.40 & 0.34 & 0.30 \\
\hline 100 & 1.0 & 0.79 & 0.65 & 0.48 & 0.37 & 0.33 \\
\hline
\end{tabular}

İlk $30 \mathrm{~cm}$ y1kama suyu ile $20 \mathrm{~cm}$ derinlikte tuzlarin \%49'u, $100 \mathrm{~cm}$ 'de ise \%21'i y1kanırken $300 \quad \mathrm{~cm}$ y1kama suyu uygulandığında üst toprakta, (40 cm derinlik) 


\section{Burdur Gölü Çevresindeki Tuzlu ve Borlu Toprakların Islahı İçin Gerekli Yıkama Suyu Miktarı ve Islah Süresi}

$\% 75,100 \mathrm{~cm}$ derinlikte ise \%60 tuz y1kanmas1 olmuştur (Çizelge 4, Şekil 2).

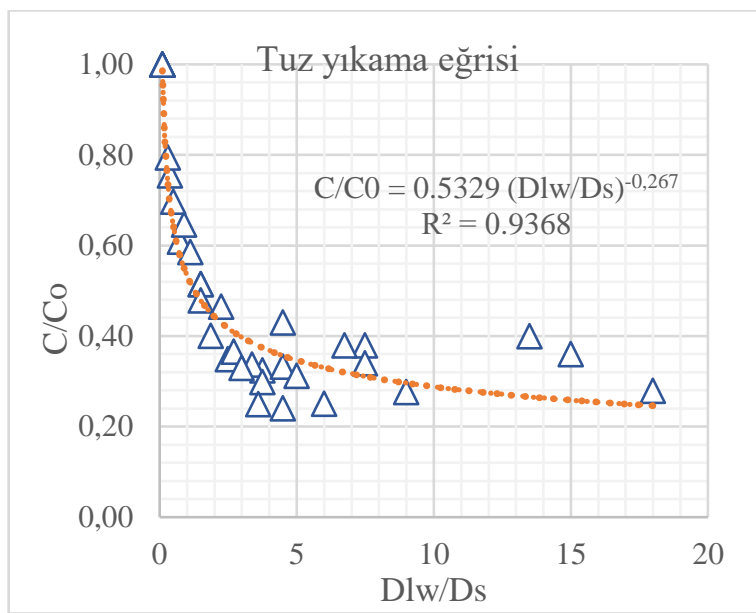

Şekil 2. Yıkama suyu derinliğinin toprak derinliğine oranı $\left(\mathrm{D}_{\mathrm{lw}} / \mathrm{D}_{\mathrm{s}}\right)$ ile başlangıca göre toprakta kalan tuz yüzdesi $\left(\mathrm{C} / \mathrm{C}_{0}\right)$ arasındaki ilişki

Testlerde toplanan tüm verilerin değerlendirilmesiyle, yıkama suyu derinliğinin $\left(D_{1 \mathrm{w}}\right)$, toprak derinliğine $\left(D_{s}\right)$ oran1, ve yıkama sonrası toprak tuzluluğu (C) ile başlangıç tuzluluğu $\left(\mathrm{C}_{0}\right)$ oranı arasındaki ilişkiyi tanımlayan regresyon analizi ile elde edilen üssel eşitlik aşağıda verilmiştir.

Anılan eşitlik istatistiksel olarak 0.01 seviyesinde önemli olup yüksek bir regresyon katsayısına sahiptir (Şekil 2).

$\mathrm{C} / \mathrm{C}_{0}=0.5329 \mathrm{D}_{\mathrm{lw}} / \mathrm{D}_{\mathrm{s}}{ }^{-0.267} ; \mathrm{R}^{2}=0.937 * *$

\section{Bor yıkanması}

Deneme sahası toprakları yüksek düzeyde bor içermektedir. Yıkama suları verilmeden önce toprak bor konsantrasyonu $100 \mathrm{~cm}$ profilde ortalama 11-12 $\mathrm{mg} \mathrm{l}^{-1}$ civarındadır. Y1kama suyu uygulaması ile özellikle üst toprakta olmak üzere tüm katmanlarda bor konsantrasyonları azalmıştır. Veriler toprak profilinde birikmiş borun uygulanan yıkama suyu ile alt katmanlara yıkandığını göstermektedir.

Çizelge 5. Farklı yıkama suyu miktarları ile toprak bor durumu

\begin{tabular}{|c|c|c|c|c|c|c|}
\hline \multirow{2}{*}{$\begin{array}{c}\text { Derinlik } \\
\mathrm{cm}\end{array}$} & \multicolumn{6}{|c|}{ Y1kama suyu derinliği $\left(\mathrm{D}_{\mathrm{s}}\right), \mathrm{cm}$} \\
\cline { 2 - 7 } & 0 & 30 & 90 & 150 & 270 & 300 \\
\hline $0-20$ & 11.31 & 5.27 & 2.41 & 3.33 & 2.51 & 1.37 \\
\hline $20-40$ & 12.66 & 10.64 & 7.24 & 8.07 & 7.32 & 4.21 \\
\hline $40-60$ & 10.67 & 10.67 & 10.14 & 11.41 & 8.22 & 7.12 \\
\hline $60-80$ & 16.33 & 11.44 & 12.12 & 12.10 & 13.5 & 8.46 \\
\hline $80-100$ & 15.75 & 11.81 & 12.03 & 11.90 & 11.37 & 9.46 \\
\hline \multicolumn{7}{|c|}{} \\
\hline 20 & 11.3 & 5.3 & 2.4 & 3.3 & 2.5 & 1.4 \\
\hline 40 & 12.0 & 8.0 & 4.8 & 5.7 & 4.9 & 2.8 \\
\hline 60 & 11.5 & 8.9 & 6.6 & 7.6 & 6.0 & 4.2 \\
\hline 80 & 12.7 & 9.5 & 8.0 & 8.7 & 7.9 & 5.3 \\
\hline 100 & 13.3 & 10.0 & 8.8 & 9.4 & 8.6 & 6.1 \\
\hline
\end{tabular}




\section{Burdur Gölü Çevresindeki Tuzlu ve Borlu Toprakların Islahı İçin Gerekli Yıkama Suyu Miktarı ve Islah Süresi}

Çizelge 6. Yıkama sularına karşı toprakta kalan tuz yüzdesi

\begin{tabular}{|c|c|c|c|c|c|c|}
\hline 20 & 1.0 & 0.47 & 0.21 & 0.29 & 0.22 & 0.12 \\
\hline 40 & 1.0 & 0.66 & 0.40 & 0.48 & 0.41 & 0.23 \\
\hline 60 & 1.0 & 0.77 & 0.57 & 0.66 & 0.52 & 0.37 \\
\hline 80 & 1.0 & 0.75 & 0.63 & 0.68 & 0.62 & 0.42 \\
\hline 100 & 1.0 & 0.75 & 0.66 & 0.70 & 0.64 & 0.46 \\
\hline
\end{tabular}

İlk y1kamalarda bor üst topraktan alt toprak katmanlarına yıkanarak profilden uzaklaşmıştır. Üst katmanda $11.3 \mathrm{mg} \mathrm{l}^{-1}$ olan bor konsantrasyonu $300 \mathrm{~cm}$ yıkama suyu sonunda $1.37 \mathrm{mg} \mathrm{l}^{-1}$ ye düşmüştür (Çizelge 5). Y1kama suyu uygulamalarının başlangıcında bor konsantrasyonu hizla azalırken. $150 \mathrm{~cm}$ yıkama suyu uygulamasından sonra yıkanma hızı görece yavaşlamıştır.

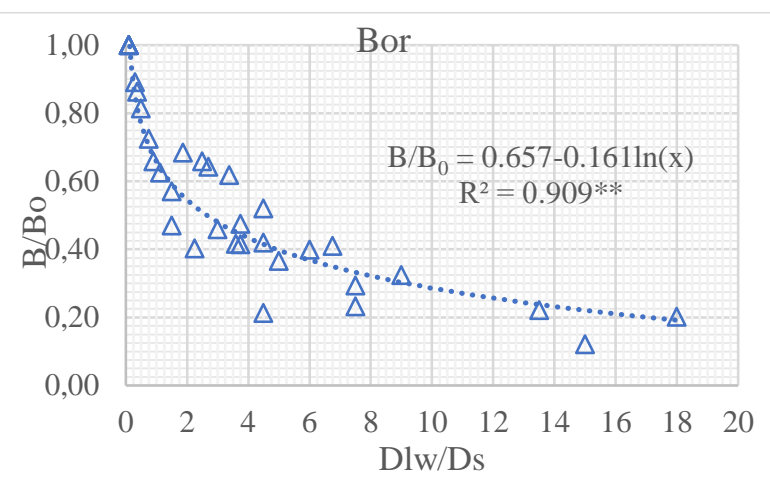

Şekil 3. Yıkama suyu derinliğinin toprak derinliğine oranı $\left(\mathrm{D}_{\mathrm{lw}} / \mathrm{D}_{\mathrm{s}}\right)$ ile başlangıca göre toprakta kalan tuz yüzdesi $\left(\mathrm{B} / \mathrm{B}_{0}\right)$ arasındaki ilişki

İlk $30 \mathrm{~cm}$ yıkama suyu ile $20 \mathrm{~cm}$ derinlikte bor konsantrasyonu \%53, $100 \mathrm{~cm}$ 'de ise \%25 azalırken, $300 \mathrm{~cm}$ yıkama suyu ile üst toprakta, yani $20 \mathrm{~cm}$ derinlikte, mevcut borun $\% 88^{\prime} \mathrm{i}, \quad 100 \mathrm{~cm}$ derinlikte ise \%54'ü yıkanmıştır (Çizelge 6, Şekil 3).

Test sonunda elde edilen verilerle yapilan regresyon analizi sonucunda

$\mathrm{B} / \mathrm{B}_{0}=0.657-0.161 \ln (\mathrm{x}) ; \mathrm{R}^{2}=0.909 * *$

eşitliği ile ifade edilen logaritmik ilişki bulunmuştur. Bor yıkaması için gerekli olan su derinliği, bahsi geçen ilişki ve Şekil 3 kullanılarak hesaplanabilir. Örneğin Şekil 3 kullanilarak toprakta mevcut borun \%50'sini uzaklaştırmak için toprak derinliğinin yaklaşık 3 katı yıkama suyu gerektiği kolayca hesaplanabilir.

\section{Islah süresi}

Yıkama sularının parsellere veriliş ve çekiliş saatleri kaydedilerek suyun toprağa infiltre olma süreleri belirlenmiştir (Çizelge 7).

Eklenik yıkama suyu derinlikleri ile eklenik zaman arasında yapılan regresyon analizi sonucunda yüksek bir bağdaşım katsayına sahip aşağıdaki eklenik infiltrasyon eşitliği;

$\mathrm{Z}=9.623 \mathrm{~T}^{0.774} ; \mathrm{R}^{2}=0.999 * *$ elde edilmiştir (Şekil. 4).

Çizelge 7. İnfiltre olan su derinliği (Z,) ve zaman (T).

\begin{tabular}{|c|c|c|c|c|c|c|c|c|c|c|}
\hline $\mathrm{T}$, gün & 4.5 & 11 & 17 & 25 & 34 & 43 & 54 & 66 & 76 & 87 \\
\hline $\mathrm{Z}, \mathrm{cm}$ & 30 & 60 & 90 & 120 & 150 & 180 & 210 & 240 & 270 & 300 \\
\hline
\end{tabular}




\section{Burdur Gölü Çevresindeki Tuzlu ve Borlu Toprakların Islahı İçin Gerekli Yıkama Suyu Miktarı ve Islah Süresi}

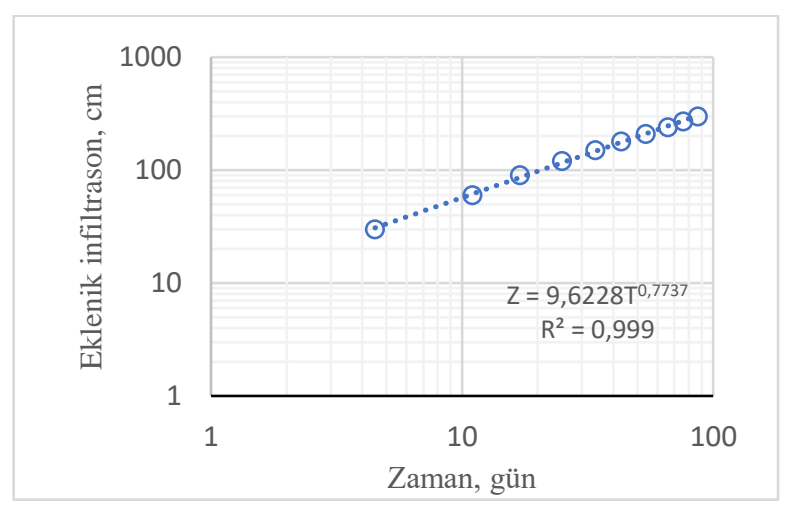

Şekil 4. Toprağın infiltrasyon kapasitesi

\section{Tuz yıkanması için ıslah süresi}

Tuz yıkama eğrisi kullanılarak $20 \mathrm{~cm}$ toprak derinliğginde $\mathrm{EC}_{\mathrm{e}}$ değerini 6-7 $\mathrm{dS} \mathrm{m}^{-1}$ 'e düşürülmesi halinde arpa ve şeker pancarı gibi tuza dayanıklı bitkiler yetiştirilebilir. Bu durumda tuz yıkama eşitliğinin farklı derinlikler için çözümü ile gerekli yıkama suyu miktarları aşağıdaki gibi hesaplanır.

$\mathrm{C}_{0}=13.6 ; \mathrm{C}=6$, ve buradan;

$\mathrm{C} / \mathrm{C}_{0}=6 / 13.6=0.44$ bulunur. Başka bir anlatımla topraktaki tuzun \%46 sinın yıkanması gerekir.

$\mathrm{Bu}$ değer tarla denemesi ile belirlenen $\mathrm{C} / \mathrm{C}_{0}=$ $0.5329 \mathrm{D}_{\mathrm{lw}} / \mathrm{D}_{\mathrm{s}}{ }^{-0.267}$; tuz yıkama eşitliğinde yerine konarak çözülürse, $0.44=0.5329 \mathrm{D}_{\mathrm{lw}} / \mathrm{D}_{\mathrm{s}}^{-0.267}$
$\mathrm{D}_{\mathrm{lw}} / \mathrm{D}_{\mathrm{s}}=2.0$ bulunur. Buradan y1kama suyu derinliği $\mathrm{D}_{\mathrm{lw}}$; farklı toprak derinlikleri için

$\mathrm{D}_{\mathrm{t}}=20 \mathrm{~cm}$ için, $\mathrm{D}_{\mathrm{lw}}=2 \times 20=40 \mathrm{~cm}$,

$D_{t}=30 \mathrm{~cm}$ için, $D_{l w}=2 \times 30=60 \mathrm{~cm}$

$D_{t}=40 \mathrm{~cm}$ için, $D_{l w}=2 \times 40=80 \mathrm{~cm}$ yıkama suyu derinliği bulunur.

Tuz ve bor fazlalığının giderilmesi ve uygulanan yıkama sularının infiltre olması için gerekli süre, denemelerle elde edilen eklenik infiltrasyon eşitliği veya infiltrasyon grafiği kullanılarak ıslah süresi aşağıdaki gibi hesaplanmıştır.

$\mathrm{Z}=9.6228 \mathrm{~T}^{0.774}$;

$\mathrm{Z}=40=9.6228 \mathrm{~T}^{0.774}$,

$\mathrm{T}^{0.774}=40 / 9.628=4.15$ ve buradan; $\mathrm{T}_{\text {net }}=6.3$ gün bulunur.

Her yıkamada $10 \mathrm{~cm}$ su verileceği ve yıkama uygulamaları arasında 3 gün kuruma dönemi bırakılacağ1 varsayılarak. $\mathrm{D}_{\mathrm{t}}=20 \mathrm{~cm}$ toprak derinliği için sslah süresi, $\mathrm{T}_{\text {sl }}$;

$\mathrm{T}_{1 \mathrm{sl}}=\mathrm{T}_{\mathrm{n}}+\left(\mathrm{D}_{\mathrm{lw}} / 10\right) \times 3$ eşitliği ile

$\mathrm{T}_{1 \mathrm{sl}}=6.3+(40 / 10) \times 3=6.3+4 \times 3=18.3$ gün olarak bulunur. Aynı işlemler diğer toprak derinlikleri ile hesaplanarak Çizelge 8'de verilmiştir

Çizelge 8. Tuzlu topraklar için yıkama suyu derinliği ve yıkama süresi

\begin{tabular}{|c|c|c|c|c|c|c|c|}
\hline $\mathrm{Ds}, \mathrm{cm}$ & $\mathrm{C}_{0}$ & $\mathrm{C}$ & $\mathrm{C}_{\mathrm{C}}$ & $\mathrm{D}_{\mathrm{lw}} / \mathrm{D}_{\mathrm{s}}$ & $\mathrm{D}_{\mathrm{lw}}, \mathrm{cm}$ & $\mathrm{T}_{\mathrm{n}}$, gün & $\mathrm{T}_{\text {isl }}$ \\
\hline 20 & 13.6 & 6 & 0.44 & 2.0 & 40 & 6.3 & 18 \\
\hline 40 & 13.6 & 6 & 0.44 & 2.0 & 80 & 15.4 & 47 \\
\hline 60 & 13.5 & 6 & 0.44 & 2.0 & 120 & 25.6 & 73 \\
\hline
\end{tabular}

\section{Bor yıkanması için ıslah süresi}

Bora dayanıklı yonca ve şeker pancarı yetiştirileceği varsayılarak, bor değerinin $6 \mathrm{mg} \mathrm{l}^{-1}$ ' ye düşürülmesinin başlangıç için yeterli olacağ varsayılmıştır.
$\mathrm{Bu}$ durumda üst toprağın $20 \mathrm{~cm}$ toprak derinliğinde bor ıslahı için $44 \mathrm{~cm}$ yıkama suyu ve 20 gün gerekirken, $40 \mathrm{~cm}$ derinlik için, 108 $\mathrm{cm}$ su ve 54 gün, $60 \mathrm{~cm}$ toprak derinliği için $144 \mathrm{~cm}$ yıkama suyu ve 76 gün gerekli olduğu 


\section{Burdur Gölü Çevresindeki Tuzlu ve Borlu Toprakların Islahı İçin Gerekli Yıkama Suyu Miktarı ve Islah Süresi}

bulunur (Çizelge 9).

\section{Tartışma}

Türkiye'nin değişik birçok ovasında yürütülen tarla denemeleri benzer sonuçlar üretmiştir. $\mathrm{Bu}$ durumun denemelerin yürütüldüğü toprakların ağır kil bünyeli olmaları ve tuzluluğun yanında yüksek düzeyde değişebilir sodyum içeriğine sahip olmalarından kaynaklandığ söylenebilir (Beyce, 1977; Bahçeci, 1983. Bahçeci, 1984.; Özden ve Ören, 1986; Saatçılar, 1991; Sönmez ve ark., 1996).

Aralıklı göllendirme yöntemi ile yapılan bu deneme ile Burdur yöresindeki tuzlu ve borlu toprakların 1slahının oldukça zaman alıcı ve fazla miktarda suya gerek duyulduğunu göstermiştir. Toprakların ağır bünyeli ve değişebilir sodyum içeriklerinin yüksek olması nedeniyle infiltrasyon hızları çok düşüktür. $\mathrm{Bu}$ yüzden uygulanan yıkama sularının önemli bir bölümü buharlaşma ve yanal sızmalarla kaybolmaktadır. Bu yüzden uygulanan sularin tuz ve bor yıkanmasin etkisi azalmaktadır. Parsel alanlarının büyüklüğünün oranında yanal sızmaların oranı küçülecektir. Ayrıca 1slah uygulamalarının sicak yaz mevsimi yerine, sonbahar ve kış döneminde yapılması buharlaşmanın olumsuz etkisini azaltacaktır.

\section{Sonuç}

Başlangıç tuz konsantrasyonunun, dolayısıyla giderilmesi gerekli tuz yüzdesinin yüksek olması nedeniyle, tuz yıkanması için daha fazla suya ve zamana ihtiyaç duyulduğu bulunmuştur. $\mathrm{EC}_{\mathrm{e}}$ değeri $4 \mathrm{dS} \mathrm{m}^{-1}$ ve bor değeri $2 \mathrm{mg} \mathrm{l}^{-1}$ 'ye düşürülmesi hedeflenirse, bu durumda tuz yıkanması için toprak derinliğinin yaklaşık 9 katı su gerekli olduğu bulunmuştur.

Çizelge 9. Borlu toprakların 1slahı için gerekli yıkama suyu derinliği ve 1slah süresi

\begin{tabular}{|c|c|c|c|c|c|c|c|}
\hline $\begin{array}{c}\mathrm{D}_{\mathrm{t}} \\
\mathrm{cm}\end{array}$ & $\mathrm{B}_{0}$ & $\begin{array}{c}\mathrm{B} \\
\mathrm{mg} \mathrm{l}^{-1}\end{array}$ & $\mathrm{~B} / \mathrm{B}_{0}$ & $\mathrm{D}_{\mathrm{lw}} / \mathrm{D}_{\mathrm{s}}$ & $\begin{array}{c}\mathrm{D}_{\mathrm{lw}} \\
\mathrm{cm}\end{array}$ & $\begin{array}{c}\mathrm{T}_{\mathrm{n}} \\
\text { gün }\end{array}$ & $\begin{array}{c}\mathrm{T}_{\text {sl }} \\
\text { gün }\end{array}$ \\
\hline 20 & 11.0 & 6 & 0.53 & 2.2 & 44 & 7 & 20 \\
\hline 40 & 12.0 & 6 & 0.50 & 2.7 & 108 & 23 & 54 \\
\hline 60 & 11.5 & 6 & 0.52 & 2.4 & 144 & 33 & 76 \\
\hline
\end{tabular}

Yani $20 \mathrm{~cm}$ derinlik için $180 \mathrm{~cm}, 100 \mathrm{~cm}$ toprak derinliği için $900 \mathrm{~cm}$ su gerekli olduğu hesaplanmıştır.

Aynı şekilde bor yıkanması işleminde $20 \mathrm{~cm}$ derinlik için $\mathrm{B} / \mathrm{B}_{\mathrm{o}}=0.15$ bulunur. Buna göre toprak derinliğinin 23 katı su gerektiği hesaplanmıştır. $\mathrm{Bu}$ durumda $20 \mathrm{~cm}$ toprak derinliği için $460 \mathrm{~cm}, 100 \mathrm{~cm}$ toprak derinliği için $2300 \mathrm{~cm}$ su gerekli olduğu hesaplanmıştır. Belirtilen miktarda su ve uzun 1slah süreleri işlemlerin başarısız olmasına neden olacaktır.

$\mathrm{Bu}$ yüzden toprak 1slahının başlangıcında daha az toprak derinlikleri ele alınarak, aynı zamanda tuza ve bora dayanıklı bitkilerin yetişebileceği düzeye kadar yıkama yapılması ve sonraki aşamalarda fitomeditasyonla islah çalışmalarının devam edilmesi önerilir.

\section{Teşekkür}

Yazarlar, bu çalışmanın tarla denemelerinde ve laboratuvar analizlerinde emeği geçen Konya TOPRAKSU Araştırma Enstitüsü çalışanlarına sonsuz şükranlarını sunarlar.

\section{Kaynaklar}

Abhilash, P.C., Powell, J.R., Singh, H. B., Singh, B. K. (2012) Plant-microbe interactions: Novel applications for exploitation in multi-purpose 


\section{Burdur Gölü Çevresindeki Tuzlu ve Borlu Toprakların Islahı İçin Gerekli Yıkama Suyu Miktarı ve Islah Süresi}

remediation technologies. Trends in Biotechnology, 30(8), 416-420. https://doi.org/10.1016/j.tibtech.2012.04.004

https://doi.org/10.1016/j.tibtech.2012.04.004 Amacher,

Bahçeci, İ. (1983). Aksaray Ovası Tuzlu Sodyumlu Topraklarının Islahı İçin Gerekli Yıkama Suyu, Islah Maddesi Miktarı ve Islah Süresi. Bölge Topraksu Araştırma Enstitüsü Yayınları. Genel Yayın No. 97 Rapor Seri No. 69 Konya.

Bahçeci, İ. (1984). Konya Ereğli Ovası Tuzlu Sodyumlu Borlu Topraklarının Islahı İçin Gerekli Y1kama Suyu, Islah Maddesi Miktarı ve Islah Süresi. Köy Hizmetleri Araştırma Enstitüsü Yayınları. Genel Yayın No.115. Rapor Seri No: 89, Konya.

Beyce, Ö. (1977) Türkiye'nin Bazı Sulama Developman Alanlarındaki Tuzlu ve Sodyumlu Topraklarda Yıkama Suyu ve Islah Maddesi Miktarının Saptanması Üzerine Bir Araştırma. Merkez Topraksu Araştırma Enstitüsü Yayınları. Genel Yayın No.44. Rapor Seri No.25 Ankara

Bouyoucos, G. S. (1951). A recalibration of the hydrometer method for making mechanical analysis of soils. Agronomy Journal 43: 434-448. s.

Chaturvedi, A. N., Jain, R. K., Garg, V. K. (1987) Afforestation of usersoils-A case study. In R. S. Rana (Ed.), Afforestation of salt-affected soils. International Symposium Paper No. 3 (pp. 163-178). Karnal, India:Central Soil Salinity Research Institute.

Dagar, J. C., Tomar, O. S., Kumar, Y., Bhagwan, H., Yadav, R. K., Tyagi, N. K. (2006) Performance of some under-explored cropsunder saline irrigation in a semiarid climate in Northwest India LandDegradation \& Development, 17, 285-2, 99. https://doi.org/ 10.1002/ ldr.712 Das

Dielman, P.J. (Ed.) (1963) Reclamation of Salt Affected Soils in Iraq. International Institute for Land Reclamation and Improvement, Wageningen. Publication 11. 175 P
DSİ. (2016). Burdur Havzas1 Master Plan Nihai Raporu. Ankara: Devlet $\mathrm{Su}$ İşleri Genel Müdürlüğü.

Dubey, R. K., Dubey, P. K., Abhilash, P. C. (2019) Sustainable soilamendments for improving the soil quality, yield and nutrient contentof Brassica juncea (L.) grown in different agroecological zones of east-ern Uttar Pradesh, India. Soil and Tillage Research, 195, 104418.https://doi.org/10.1016/j.still.2019.104 418

Edrisi, S. A., El-Keblawy, A., Abhilash, P. C. (2020) Sustainabilityanalysis of Prosopis juliflora (Sw.) DC based restoration of degradedland in North India. Land, 9(2), 59. https://doi.org/10.3390/land9020059

FAO (2021) Global map of salt-affected soils, 20p, Food and Agricultural Organization of the United Nations Rome, Italy.

Hoffman, G. J. (1986) Guidelines for reclamation of salt-affected soils. Applied agricultural Research 1 (2):65-72

Kovda, V. A. (1967) The Use of Drainage To Prevent Salinization of İrrigated Soils. Trans. 3rd. Congress.

Liu, D., Fang, S., Tian, Y., Dun, X. (2012) Variation in rhizosphere soilmicrobial index of tree species on seasonal flooding land: An in siturhizobox approach. Applied Soil Ecology, $59,1-11$, https://doi.org/10.1016/j.apsoil.2012.03.014

Mishra, A., Sharma, S. D., Khan, G. H. (2002) Rehabilitation of degradedsodic lands during a decade of Dalbergia sissoo planta tion in SultanpurDistrict of Uttar Pradesh, India. Land Degradation \& Development, 13,375-386.

Nielsen, D.R., Biggar, J.W., And Luthin , J.N., 1966. Desalinization of Soils Under Controlled Unsaturated Conditions. Int. Commission on Irrigation And Drainage, 6 th Congress, New Delhi, India

Oster, J.D., Willardson, L.S. and Hoffman, G.J., 1972. Sprinkling and Ponding Techniques for Reclaiming Saline Soils. Transactions ASCE, 15:1115-1117. 


\section{Burdur Gölü Çevresindeki Tuzlu ve Borlu Toprakların Islahı İçin Gerekli Yıkama Suyu Miktarı ve Islah Süresi}

Özden, D. M., Ören, E. (1986) Iğdır Ovası Tuzlu Sodyumlu ve Borlu Topraklarının Islahı İçin Gerekli Jips İhtiyac1, Yıkama Suyu Miktarı ve Y1kama Süresinin Saptanması. Köy Hizmetleri Araştırma Enstitüsü Yayınları. Genel Yayın No.12. Rapor Seri No. 9 Erzurum

Pessarakli, M., Szabolcs, I. (1999) Soil salinity and sodicity as particularplant/crop stress factors. In M. Pessarakli (Ed.), Handbook of plant andcrop stress (pp. 3-21). New York, NY:

Reeve, R. C. (1955) The Relations of Salinity To Irrigation and Drainage-Requirement. Trans. 3rd Congr. on Irrigation And Drainage

Richards, L. A. (1954) Diagnosis and Improvement of Saline and Alkaline Soils, United States Salinity Staff, Agricultural Handbook 60, US Department of Agriculture, Washington DC.

Saatçılar, M. (1991) Denizli Sarayköy Ovasında Doğal Jips İçeren Tuzlu Sodyumlu Toprakların Islahı İçin Gerekli Yıkama Suyu Miktarı ve Y1kama Süresi. Köy Hizmetleri Menemen Araştırma Enstitüsü. Genel Yayıı No.175.Seri No.116. Denizli

Sharma, P. C., Kaledhonkar, M. J., Immappa, K., Chaudhari, S. K. (2016) Reclamation of waterlogged saline soils through subsurface drainage technology. In ICAR-Central Soil Salinity Research Institute (ICARCSSRI),Karnal, Technology Folder 02 (pp. 0204). Haryana, India: ICAR-Central Soil Salinity Research Institute. https://doi.org/10.1002/ldr.511Montanarella

Sönmez, B., A. Ağar, İ. Bahçeci, A. Mavi, A. Yarpuzlu, 1996. Türkiye Çorak Islahı Rehberi. Başbakanlık, KHGM APK Dairesi Başkanlığı, Toprak ve Su Kaynakları Araştırma Şube Müdürlüğü Yayın No: 98 Rehber No: 12, ANKARA.

TOPRAKSU (1975) Topraksu İstatistik Bülteni, TOPRAKSU Genel Müdürlüğü Yayın No: 305. ANKARA

Tripathi, V., Edrisi, S. A., Chaurasia, R., Pandey, K. K., Dinesh, D., Srivastava, R., Abhilash, P. C.
(2019) Restoring HCHs polluted landas one of the priority activities during the UNinternational decade onecosystem restoration (2021-2030): A call for global action. Science ofthe Total Environment, 689, 1304-1315. https://doi.org/10.1016/j.scitotenv.2019.06.444

Van Hoorn, J.W. ve Van Alpen, J.G. (1990) "Salinity Control, Salt Balance and Leaching Requirement of Irrigated Soil- 9," International Course of Land Drainage, Wageningen, the Netherlands.

Utset, A., Borroto, M. (2001) A modeling-GIS approach for assessingirrigation effects on soil salinisation under global warming conditions.Agriculture Water Management, 50,53-63. https://doi.org/10.1016/S0378$\underline{3774(01) 00090-7}$ 
Burdur Gölü Çevresindeki Tuzlu ve Borlu Toprakların Islahı İçin Gerekli Yıkama Suyu Miktarı ve Islah Süresi 